\title{
The Effects on the Ego-resilience of Female Middle School Students' Based on their Participation in School Sports Club
}

\author{
Deajung Lee ${ }^{1}$, Seungman Lee ${ }^{2}$ and Hohyun Song ${ }^{3}$ \\ ${ }^{1}$ Jeonju Peonghwa middle school, Korea \\ ${ }^{2,3}$ Korea National University of Education, Korea \\ Idleownd23@hanmail.net, ${ }^{3}$ hohyunss@nate.com
}

\begin{abstract}
The objective of this study was to examine the effect of middle school girl's participation experience in school sports club on ego-identity. For this, the data of 640, 382 female students participating in the school sports club and 258 female students non-participating in the school sports club were collected. Collected data were statistically processed using the SPSS V. 20.0 program, frequency analysis, reliability analysis, $t$-test, one-way ANOVA, and post hoc test were conducted. Study results are as follows: first, there was a statistically significant difference in all sub-factors of ego-identity of middle school girl according to the participation of school sports club. Second, there was a statistically significant difference in all sub-factors of ego-identity of middle school girl according to the participation period of school sports club. Third, there was a statistically significant difference in all sub-factors of ego-identity of middle school girl according to the participation frequency per week of school sports club. Fourth, there was a statistically significant difference in all sub-factors of egoidentity of middle school girl according to the participation frequency of school sports club tournaments. Fifth, there was a statistically significant difference in all sub-factors of egoidentity of middle school girl according to the tournaments types of school sports club participation.
\end{abstract}

Keywords: Participation, Female, Middle school, Students, School sports club, Egoresiliency

\section{Introduction}

Ego-resiliency is a state of producing good results even in the negative situations of adaptation and development process [1] and refers to the capacity of maintaining or improving psychological balance even in challenging circumstances [2]. People with high ego-resiliency reduce psychological distress by positively evaluating the external stimuli and environment in the stressful situations [3] and are not highly sensitive to stress or anxiety [2]. In consideration of these characteristics of ego-resiliency, there is a need to seek a way of reinforcing this quality in adolescents who are readily exposed to and are easily affected by stress when it arises. It is believed that these mechanisms of ego-resilience can be experienced naturally in sporting activities. The experience of participating in voluntary and autonomous school sports clubs is expected to further enhance ego-resilience. It is because

Article History:

Received (November 13, 2019), Review Result (December 27, 2019), Accepted (January 29, 2020) 
school sports club activities contribute to developing, not only students' health and physical strength, but also self-discipline, coping skills, and planning skills [4][5].

Being limited to the sphere of participation in school sports clubs and the development of ego-resilience [6], concluded that students who participated in school sports club activities experienced a decrease in deviant behaviors by reducing their aggression and strengthening their ego- resiliency. In addition, the studies of [7] show that participation in school sports clubs has had a positive influence on the ego-resilience of middle school students and contributed to a positive development in their attitudes towards physical education as a subject.

These studies are significant in that they can be used as a resource to teach adolescents coping mechanisms when they are exposed to stressors where their psychological anxiety increases due to drastic changes and they are vulnerable to serious adaptation problems due to internal conflicts and confusion [8]. Nonetheless, the reality is that there are fewer studies regarding the participation in school's sports club activities and ego- resiliency development than those studying the crisis of mental health problems in adolescents. In this regard, it is vital to identify the influence that participation in school sports clubs have on the development of ego-resiliency.

This study was oriented only to female students, considering that more female students (50.0\%) feel seriously stressed compared to the number of male students $(37.3 \%)$ in terms of the stress recognition level related to mental health of adolescents [9]. Also female students experience more stress related to academic performance in terms of grades, careers, tests, and classes than male students [10].

\section{Research methods}

\subsection{Participants}

This study selected middle school girls from 5 schools from Jeonbuk, 2 from Chonbuk 2, 2 from Jeonnam, 2 form Chungnam, 2 from Gyenoggi, 1 from Gangwon, 1 from Jeju Island and 1 from Seoul as the subjects of the study. Among the 1230 questionnaires collected, 1187 questionnaires of the data were used for the final analysis, except for 43 questionnaires of the questionnaires that were not answered insincerely or were missing in the inspection items.

Table 1. Demographic features of research participants

\begin{tabular}{|c|c|c|c|}
\hline \multicolumn{2}{|c|}{ Division } & Frequency $(\mathrm{N})$ & Percentage $(\%)$ \\
\hline \multirow{3}{*}{ School year } & 1 & 350 & 29.5 \\
\cline { 2 - 4 } & 2 & 378 & 31.8 \\
\cline { 2 - 4 } & 3 & 459 & 38.7 \\
\hline \multirow{3}{*}{ Participation status } & YES & 602 & 50.7 \\
\cline { 2 - 4 } & NO & 585 & 49.3 \\
\hline \multirow{3}{*}{$\begin{array}{c}\text { Participation period } \\
\text { Frequency of weekly participation } \\
\text { over the previous year }\end{array}$} & $<6$ months & 153 & 25.4 \\
\cline { 2 - 4 } & $6-12$ months & 147 & 24.4 \\
\cline { 2 - 4 } & $1-2$ years & 156 & 25.9 \\
\cline { 2 - 4 } & $>3$ years & 146 & 24.3 \\
\cline { 2 - 4 } & Once & 178 & 29.6 \\
\hline
\end{tabular}




\begin{tabular}{|c|c|c|c|}
\hline \multirow{3}{*}{$\begin{array}{c}\text { Frequency of participation in } \\
\text { competitions }\end{array}$} & Once & 158 & 26.2 \\
\cline { 2 - 4 } & $2-3$ times & 228 & 37.9 \\
\cline { 2 - 4 } & $>4$ times & 216 & 35.9 \\
\hline \multirow{3}{*}{\begin{tabular}{c} 
Types of Competition \\
\cline { 2 - 4 }
\end{tabular}} & City/ county & 159 & 26.4 \\
\cline { 2 - 4 } & Provincial & 250 & 41.5 \\
\cline { 2 - 4 } & National & 193 & 32.1 \\
\hline
\end{tabular}

\subsection{Measurement tools}

This study used the Korean-type ego-resilience questionnaire of [11]. The questionnaire is composed of 5 factors, each factor dealing with different aspects of ego-resiliency. According to the results, a total of 39 questions were divided into 5 factors; positive thinking (32.956\%), problem solving $(9.445 \%)$, autonomous behavior $(8.720 \%)$, affiliative behavior $(6.235 \%)$ and emotion control (5.840\%). The cumulative dispersion turned out to be $63.196 \%$ and the factor loading of each factor was above .05 , with a level of reliability up to $.819-.937$ being recorded.

\subsection{Data processing method}

The collected questionnaires were coded on a computer and processed using the SPSS statistical program. First, the validity and reliability were analyzed using the exploratory factor analysis and Cronbach's coefficient method based on the Varimax rotation. Secondly, with a view to investigate the difference in middle school female students' ego resilience according to the degree of their participation in school sports clubs, this study carried out independent t-test and A one-way ANOVA and the Scheffe test for post hoc verification.

\section{Results}

(1) Difference in ego-resiliency of female middle school students according to the status of participation in school sports club

The results of analysis of variance for verifying this fact show that participants in school sports clubs manifested significant differences in all factors by subordinate factors of egoresiliency as compared with others who do not participate in it. The results are shown in [Table 2].

Table 2. Difference in ego-resiliency of female middle school students according to the status of participation in school sports club

\begin{tabular}{|c|c|c|c|c|}
\hline \multirow{2}{*}{ Ego-resiliency } & \multicolumn{2}{|c|}{ Participation status $(\mathrm{n}=1187)$} & \multirow{2}{*}{$\mathrm{t}$} & \multirow{2}{*}{$p$} \\
\cline { 2 - 3 } & \multicolumn{2}{|c|}{ YES $(\mathrm{n}=602)$} & $\mathrm{NO}(\mathrm{n}=585)$ & \\
\cline { 2 - 5 } & \multicolumn{2}{|c|}{ Mean and standard deviation } & -8.446 & .000 \\
\hline Positive thinking & $37.19 \pm 6.83$ & $41.69 \pm 5.64$ & -.6 .904 & .000 \\
\hline Problem solving & $29.57 \pm 5.07$ & $32.72 \pm 5.71$ & -6.303 & .000 \\
\hline Affiliative behavior & $25.57 \pm 4.42$ & $27.81 \pm 4.18$ & -6.167 & .000 \\
\hline Emotion control & $19.27 \pm 4.25$ & $21.33 \pm 3.84$ & -4.700 & .000 \\
\hline Autonomous behavior & $23.48 \pm 3.75$ & $25.08 \pm 4.55$ & & \\
\hline
\end{tabular}


(2) Difference in ego-resiliency of female middle school students according to period of participation in school sports clubs

As [Table 3] shows, it turned out that there are significant differences in all subordinate factors of ego-resiliency according to the period of participation in school sports clubs.

Table 3. Difference in ego-resiliency of female middle school students according to period of participation in school sports club

\begin{tabular}{|c|c|c|c|c|c|c|c|}
\hline \multirow{3}{*}{ Ego-resiliency } & \multicolumn{4}{|c|}{ Participation period $(n=602)$} & \multirow{3}{*}{$\begin{array}{c}\mathrm{F} \\
\text { value }\end{array}$} & \multirow{3}{*}{$p$} & \multirow{3}{*}{ Post-hoc } \\
\hline & $A(n=153)$ & $\mathrm{B}(\mathrm{n}=147)$ & $C(n=156)$ & $\mathrm{D}(\mathrm{n}=146)$ & & & \\
\hline & \multicolumn{4}{|c|}{ Mean and standard deviation } & & & \\
\hline Positive thinking & $40.38 \pm 5.85$ & $41.42 \pm 4.58$ & $42.87 \pm 5.36$ & $42.36 \pm 5.95$ & 3.877 & .009 & $\mathrm{~A}<\mathrm{C}$ \\
\hline Problem solving & $30.87 \pm 5.77$ & $30.83 \pm 4.37$ & $33.73 \pm 5.48$ & $35.01 \pm 5.54$ & 14.744 & .000 & $\mathrm{~A}, \mathrm{~B}<\mathrm{C}, \mathrm{D}$ \\
\hline Affiliative behavior & $26.66 \pm 4.07$ & $27.36 \pm 3.01$ & $28.33 \pm 4.22$ & $28.89 \pm 4.55$ & 6.318 & .000 & $\mathrm{~A}<\mathrm{D}$ \\
\hline Emotion control & $20.00 \pm 3.32$ & $20.61 \pm 2.40$ & $21.78 \pm 4.16$ & $22.76 \pm 4.23$ & 12.141 & .000 & $\begin{array}{c}\mathrm{A}<\mathrm{C}, \mathrm{D} \\
\mathrm{B}<\mathrm{D}\end{array}$ \\
\hline $\begin{array}{c}\text { Autonomous } \\
\text { behavior }\end{array}$ & $23.68 \pm 4.35$ & $24.98 \pm 3.51$ & $24.91 \pm 4.28$ & $26.68 \pm 5.02$ & 8.802 & .000 & $A<D$ \\
\hline
\end{tabular}

(3) Difference in ego-resiliency of female middle school students according to frequency of participation in school sports clubs on a weekly basis

As seen in [Table 4], there were significant differences in all subordinate factors of egoresiliency, except the factor of positive thinking, based on weekly frequency of participation in school sports clubs.

Table 4. Difference in ego-resiliency of female middle school students according to the frequency of participation in weekly school sports club activities

\begin{tabular}{|c|c|c|c|c|c|c|}
\hline \multirow{3}{*}{ Ego-resiliency } & \multicolumn{3}{|c|}{ Weekly participation frequency $(n=602)$} & \multirow{3}{*}{ F value } & \multirow{3}{*}{$p$} & \multirow{3}{*}{$\begin{array}{l}\text { Post- } \\
\text { hoc }\end{array}$} \\
\hline & $\mathrm{A}(\mathrm{n}=178)$ & $\mathrm{B}(\mathrm{n}=201)$ & $C(n=223)$ & & & \\
\hline & \multicolumn{3}{|c|}{ Mean and standard deviation } & & & \\
\hline Positive thinking & $40.94 \pm 5.95$ & $41.76 \pm .5 .68$ & $42.17 \pm 5.36$ & 1.498 & .225 & \\
\hline Problem solving & $30.88 \pm 5.66$ & $32.90 \pm 5.94$ & $33.89 \pm 5.25$ & 9.181 & .000 & $\mathrm{~A}<\mathrm{C}$ \\
\hline Affiliative behavior & $26.50 \pm 4.06$ & $28.37 \pm 4.00$ & $28.32 \pm 4.22$ & 7.607 & .001 & $\mathrm{~A}<\mathrm{B}, \mathrm{C}$ \\
\hline Emotion control & $19.58 \pm 3.42$ & $22.18 \pm 3.75$ & $21.94 \pm 3.80$ & 17.000 & .000 & $\mathrm{~A}<\mathrm{B}, \mathrm{C}$ \\
\hline Autonomous behavior & $24.21 \pm 4.29$ & $24.84 \pm 4.29$ & $25.87 \pm 4.82$ & 4.487 & .012 & $\mathrm{~A}<\mathrm{C}$ \\
\hline
\end{tabular}

A: Once B: 2-3 times C More than 4 times

(4) Difference in ego-resiliency of female middle school students according to frequency of participation in school sports clubs

As [Table 5] shows, it was possible to observe significant differences in all subordinate factors of ego-resiliency except the factor of positive thinking according to frequency of participation in school sports clubs. 
Table 5. Difference in ego-resiliency of female middle school students according to frequency of participation in school sports club activities

\begin{tabular}{|c|c|c|c|c|c|c|}
\hline \multirow{2}{*}{ Ego-resiliency } & \multicolumn{2}{|c|}{ Frequency of participation in competitions (n=602) } & \multirow{2}{*}{ F value } & $P$ & $\begin{array}{c}\text { Post- } \\
\text { hoc }\end{array}$ \\
\cline { 2 - 7 } & $\mathrm{A}(\mathrm{n}=158)$ & $\mathrm{B}(\mathrm{n}=228)$ & $\mathrm{C}(\mathrm{n}=216)$ & & & \\
\cline { 2 - 7 } & \multicolumn{3}{|c|}{ Mean and standard deviation } & & & \\
\hline Positive thinking & $41.74 \pm 5.56$ & $41.00 \pm 5.88$ & $42.15 \pm 5.53$ & 1.215 & .298 & \\
\hline Problem solving & $30.51 \pm 5.11$ & $33.11 \pm 5.57$ & $34.63 \pm 5.65$ & 19.851 & .000 & $\mathrm{~A}<\mathrm{B}, \mathrm{C}$ \\
\hline Affiliative behavior & $26.69 \pm 3.80$ & $28.34 \pm 4.01$ & $28.54 \pm 4.45$ & 8.066 & .000 & $\mathrm{~A}<\mathrm{B}, \mathrm{C}$ \\
\hline Emotion control & $20.29 \pm 3.72$ & $21.19 \pm 3.54$ & $22.46 \pm 3.88$ & 11.498 & .000 & $\mathrm{~A}, \mathrm{~B}<\mathrm{C}$ \\
\hline $\begin{array}{c}\text { Autonomous } \\
\text { behavior }\end{array}$ & $23.98 \pm 4.05$ & $24.77 \pm 4.36$ & $26.38 \pm 4.86$ & 10.407 & .000 & $\mathrm{~A}, \mathrm{~B}<\mathrm{C}$ \\
\hline
\end{tabular}

(5) Difference in ego-resiliency of female middle school students according to the type of competitions school of sports clubs participated in

Table 6. Difference in ego-resiliency of female middle school students according to the type of school sports club competitions participated in

\begin{tabular}{|c|c|c|c|c|c|c|}
\hline \multirow{3}{*}{ Ego-resiliency } & Type of col & tition partici & $\mathrm{d}$ in $(n=602)$ & \multirow{3}{*}{ F value } & \multirow{3}{*}{$p$} & \multirow{3}{*}{ Post-hoc } \\
\hline & $A(n=159)$ & $\mathrm{B}(\mathrm{n}=250)$ & $C(n=193)$ & & & \\
\hline & \multicolumn{3}{|c|}{ Mean and standard deviation } & & & \\
\hline Positive thinking & $40.83 \pm 5.83$ & $41.94 \pm 4.98$ & $42.01 \pm 5.98$ & 1.475 & .230 & \\
\hline Problem solving & $29.34 \pm 4.28$ & $31.57 \pm 4.79$ & $35.64 \pm 5.70$ & 49.852 & .000 & $\mathrm{~A}<\mathrm{B}<\mathrm{C}$ \\
\hline Affiliative behavior & $25.36 \pm 3.17$ & $27.80 \pm 3.64$ & $29.29 \pm 4.43$ & 30.017 & .000 & $\mathrm{~A}<\mathrm{B}<\mathrm{C}$ \\
\hline Emotion control & $19.37 \pm 3.05$ & $21.14 \pm 3.54$ & $22.65 \pm 3.97$ & 24.302 & .000 & $\mathrm{~A}<\mathrm{B}<\mathrm{C}$ \\
\hline Autonomous behavior & $24.02 \pm 4.07$ & $24.70 \pm 3.65$ & $26.00 \pm 5.28$ & 6.315 & .002 & $\mathrm{~A}, \mathrm{~B}<\mathrm{C}$ \\
\hline
\end{tabular}

A: Competitions of City and County $B$ : Competitions of Province $C$ : Nationwide competitions

As seen in [Table 6], there were significant differences in all subordinate factors of egoresiliency, except the factor of positive thinking, according to the type of competitions of school sports clubs participated in.

\section{Conclusion}

This study aimed investigate the differences in the ego-resiliency of female middle school students throughout the country based on their participation in school sports clubs, the frequency of their participation per week, the frequency of their participation in and the type of competitions they participate in. The specific discussions based on the results of the study can be summarized as follows:

Firstly, there were statistically significant differences in all subordinate factors of egoresiliency according to the status of participation in school sports club. This result shows that female middle school students' experience of participation in school sports club has an influence on the formation of positive ego-resiliency. The study of [12] confirm that egoresiliency can be strengthened by expanding the opportunity for growth through frequent challenges, overcoming crises in the middle of these challenges, and gradually gaining a sense of belonging by engaging in group activities. Similar to the argument of [12][13] argues that middle school students by participating in school sports club can naturally strengthen their ego-resiliency through overcoming physical and psychological bias, conflicts with club 
mates, disappointment with skill acquisition and psychological discouragement caused by unconscious comparison with others. Thus, the results of this study are supported by the general mechanisms of strengthening of ego-resiliency, as shown by [12], as well as concrete experience leading to ego-resiliency reinforcement, as argued by [13]. Secondly, the longer the period of participation in school sports clubs, the more statistically significant differences in all subordinate factors of ego-resiliency were recorded. These results suggest that participation in club activities for more than one year is necessary to enhance the egoresiliency of female middle school students through participation in school sports clubs. The argument of [6] that the differences in ego-resiliency by school year among high school students participating in school sports clubs can be attributed to the efficacy of having a longer period of participation and is in line with the results of this study. Thirdly, as the frequency of participation in sports club activities increased per week, statistically greater significant differences were observed in all subordinate factors of ego-resiliency except the factor of positive thinking. The results of this study is partially supported by the study of [14] confirming that the group that participated in sports activities more than 2-3 times a week showed a higher level of ego-resiliency than the group that participated only once a week, as well as the study of [15] verifying that children who participated more than 3 times a week displayed a statistically greater significant level in all subordinate factors of ego-resiliency as compared with those with low weekly frequency of participation. Fourthly, with a higher frequency of participation in school sports club competitions, statistically greater significant differences were observed in all subordinate factors of ego-resiliency except the factor of positive thinking. Fifthly, statistically significant differences were observed in all subordinate factors of ego-resiliency except the factor of positive thinking as the frequency of participation in the higher rank competitions of school sports clubs. In general, it is challenging for the average female student to participate in competitions of provincial or national school sports clubs. It may be possible to participate in these competitions only after long-term training with their colleagues. Therefore, female students might feel a sense of accomplishment and satisfaction when they participate in higher ranking competitions. Furthermore, considering that social interaction effects can be acquired through pride and self-esteem, self-confidence of being a player representing their school when participating in external competitions of school sports clubs, recognition from peers and teachers and positive results obtained through practicing with peers of similar abilities [16], the student's egoresiliency is estimated to be strengthened since the student's experience grows deeper as she participates in higher ranking competitions. However, it is presumed that positive experiences based on a sense of accomplishment, satisfaction, self-esteem and self-confidence is not the only factor which strengthens ego-resiliency. It is believed that ego-resiliency can be strengthened by overcoming frustration, anxiety, an inferiority complex, and conflicts with colleagues and injury while spending a lot of time in training in order to participate in higher ranking competitions [13]. Sports club activities provide an opportunity of constant failure and success and the results of effort are evidently visible. It is believed that one can attain skills, create close relationships with club mates and achieve individual growth according to the amount of one's exercise and participation. The study of [17] proves that ego-resiliency is strengthened by steady close exchanges, school performance, social competency reinforcement and developmental changes. Considering all arguments, it will be necessary to encourage students to continuously participate in sports club activities to strengthen their egoresiliency. 


\section{References}

[1] A. S. Masten, "Ordinary magic: Resilience processes in development," American Psychologist, vol.56, pp.227-238, (2001) DOI: 10.1037/0003-066x.56.3.227

[2] J. Block and A. M. Kremen, "IQ and ego-resiliency: Conceptual and empirical connections and separateness," Journal of Personality and social psychology, vol.70, no.2, pp.349-361

[3] C. R. Kim, "Influences of Ego-resilience and Positive Emotions on Positive Coping," M.S. thesis, Ajou University, Suwon: Korea, (2010)

[4] R. Larson, K. Walker, and N. Pearce, "A comparison of youth-driven and adult-driven youth programs: balancing inputs form youth and adults," Journal of Community Psychology, vol.33, no.1, pp.57-74, (2005) DOI: $10.1002 /$ jcop.20035

[5] J. Graydon, "Self-confidence and self-esteem in physical education and sport," In: Clarke G., Humberstone B. (eds) Researching Women and Sport, Palgrave Macmillan, London

[6] H. W. Kim and G. H. Lee, "Analysis correlation of aggressiveness and self-resilience and school sports club participation of high school students," Journal of Korea Association for Learner-centered Curriculum and Instruction, vol.14, no.10, pp.479-499, (2014)

[7] H. J. Park and Y. S. Jo, "The impact of school sports club participation on students' self-elasticity and subject study attitudes," Journal of Korea Society of Sports Science, vol.23, no.3, pp.1129-1143, (2014)

[8] S. Y. Soh, J. Y. Ahn, D. H. Yang, and G. M. Kim, "Parental and adolescent perceptions of transitions during early adolescence: with a focus on the FGI of adolescents and parents," The Korea Journal of Youth Counseling, vol.22, no.1, pp.247-279, (2014)

[9] Statistics Korea, "Stress awareness of adolescents", http://kostat.go.kr, (2009)

[10] H. H. Kim, "Study on the relationship between academic stress and test anxiety by gender," M.S. thesis, Hankuk University of Foreign Studies, Seoul: Korea, (2009)

[11] M. H. Kim and S. H. Kim, "Development of an ego-resilience scale for middle school students," Korea Journal of Counseling, vol.11, no.1, pp.189-206, (2010)

[12] K. L. Kumper and J. F. Summerhays, "Prevention approaches to enhance resilience among high-risk youth," Annual New York Academy of Science, vol.1094, pp.151-163, (2006) DOI: 10.1196/annals.1376.014

[13] D. J. Lee, "Study on the formation of self-identity of middle school students participating in school sports club,” Ph.D. dissertation, Chonbuk National University, JeonJu: Korea, (2019)

[14] Y. K. Byun, "A comparison of ego-resilience and stress coping strategies according to adolescents' participation in sports activities,” M.S. thesis, Ewha Womans University, Seoul: Korea, (2005)

[15] T. W. Kang, "The Effects children's sports participation give to physical strength, physical self-concept and ego-resiliency,” Ph.D. dissertation, Daegu Catholic University, Daegu: Korea, (2008)

[16] S. Choi and J. W. Kim, "The Effects of Elementary School Students Participation in School Sports Clubs on Their School Violence Attitudes and Satisfaction with School Life," Journal of Korean Society for Holistic Convergence Education, vol.21, no.2, pp.131-147, (2017)

[17] S. T. Hauser and J. Allen, "Overcoming adversity in adolescence: narratives of resilience," psychoanalytic inquiry, vol.26, no.4, pp.549-576, (2006) DOI: 10.1080/07351690701310623 
The Effects on the Ego-resilience of Female Middle School Students' Based on their Participation in School Sports Club

\section{Author}
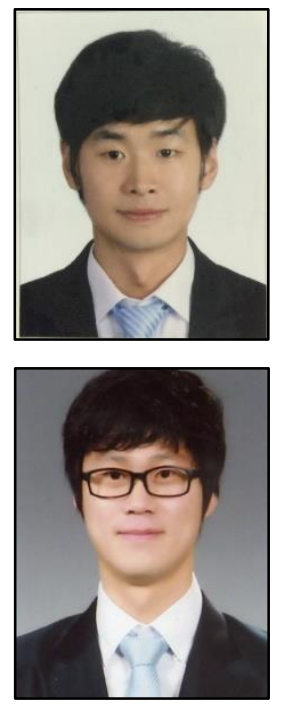

\section{Daejung Lee}

Ph.D. in education

JeonJu PyeongHwa Middle School (P.E.) Teacher

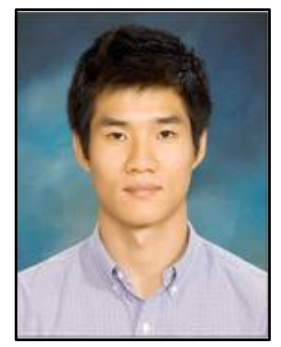

\section{Hohyun Song}

Ph.D. in education

Joenju HoSung Middle School School (P.E.) Teacher

Korea National University of Education adjunct professor 